\title{
TRADUTORES COMO ATORES E MÁGICOS ${ }^{1}$
}

\author{
Translators as Actors and Magicians
}

\author{
Dirce Waltrick DO AMARANTE \\ Universidade Federal de Santa Catarina \\ waltrickdoamarantedirce@gmail.com \\ https://orcid.org/0000-0002-5246-6844
}

\begin{abstract}
RESUMO: Comparo o tradutor ao encenador, mais especificamente ao ator, valendo-me da definição de Tadeusz Kantor para quem "o ator é um 'jogador' que joga com o texto, se distancia dele, aproxima-se dele, o abandona e o retoma, tira-lhe todo caráter anedótico para revelá-lo em sua abstração concreta. É um jogador que não sublinha a convenção do jogo, mas afirma com força sua realidade de jogador, tal como o saltimbanco ou o clown na arena do circo" (KANTOR, 2008, p. 37). A propósito do ator, lembra Kantor que, se ele "imita uma ação se coloca forçosamente acima dela. $\mathrm{O}$ ator que a executa realmente se coloca em relação a ela em posição de igualdade. É assim que se modifica a hierarquia fundamental: objeto-ator, ação-ator" (KANTOR, 2008, p. 37). A ideia do teórico do teatro polonês parece dialogar com o conceito de tradução ou transcriação de Haroldo de Campos, que se fundamenta em parte nas ideias do alemão Wolfgang Iser. Segundo Campos, é preciso desmistificar "a 'ideologia da fidelidade', a ideia servil da traduçãocópia” (TÁPIA; NÓBREGA, 2013, p. 120). É necessário pensar “a própria tradução enquanto ficção". Haroldo vale-se de um ensaio de Iser - "Os atos de fingir ou o que é fictício no texto ficcional" - para descrever e reforçar "uma 'relação triádica' que se estabelece entre o real, o fictício e o imaginário" na tradução (TÁPIA; NÓRBEGA, 2013, p. 121).
\end{abstract} PALAVRAS-CHAVE: Literatura Polonesa em Tradução; Transcriação; Teatro; Tadeusz Kantor.

ABSTRACT: I compare the translator to an actor, using as a starting point Tadeuz Kantor's definition of the actor as a "player" who plays with the text, distances himself or herself from it, comes closer to it, abandons and returns to it, takes away its anecdotal characteristics to reveal it in its concrete abstractions. This is a player that doesn't underline the conventions of the game, but vigorously affirms his/ her reality as a player, akin to the acrobat or the clown in the circus arena (KANTOR, 2008, p. 37). As for the actor, Kantor reminds us

\footnotetext{
${ }^{1}$ A tradução para a língua polonesa deste artigo foi publicada recentemente no periódico polonês “Konteksty Kultury" (Cracóvia, t. 17, z. 1, p. 112-117, 2020) .
} 
that, "if he merely imitates an action, he forcibly puts himself above it. The actor who really executes it puts himself in a position of equality to it. This is the way to modify the fundamental hierarchy: object-actor, action-actor" (KANTOR, 2008, p. 37). This thought from the Polish playwright seems to be in a dialogue with the concept of translation or transcreation of Haroldo de Campos, based in part on the ideas of German writer Wofgang Iser. According to Campos, it is necessary to de-mystify "the ideology of fidelity, the servile idea of the translation-copy" (TAPIA; NÓBREGA, 2013, p. 120). It is necessary to consider "the translation itself as a fiction. Haroldo de Campos makes use of an essay by Iser - "Acts of dissimulation or, what is fictional in a text of fiction" - to describe and reinforce "a triadic relation that evolves between the real, the fictitious and the imaginary" in the translation. (TAPIA; NÓBREGA, 2013, p. 121). KEY-WORDS: Polish Literature in Translation; Transcriation; Theatre; Tadeusz Kantor.

A primeira vez que assisti à peça $A$ classe morta (1975), do dramaturgo e encenador polonês Tadeusz Kantor (1915-1990), não foi num teatro, mas por meio de um DVD. Tratava-se da gravação de uma apresentação da peça exibida no Théâtre National de Chaillot, na França, em maio de $1989^{2}$. Na gravação, em alguns momentos, havia legendas em francês para o que se dizia em polonês; em outros não. Embora eu leia em francês, percebi que, quando não havia legenda, essa lacuna não prejudicava por completo o entendimento das cenas, que eram traduzidas pelos gestos e expressões dos atores.

Assisti à peça, diria, como seu eu fosse o narrador do conto A estação morta, do escritor polonês Bruno Schulz. No conto, o narrador descreve uma conversa entre seu pai e um estrangeiro, que falava em uma outra língua, incompreendida por ele e por outros familiares. Diz o narrador:

Sem compreender a língua estrangeira, assistíamos com respeito a essa conversa cerimoniosa, cheia de sorrisos, piscadelas, tapinhas nas costas. Após a troca das gentilezas preliminares, os senhores passaram ao assunto propriamente dito [...]. Com charutos robustos no canto da boca, o rosto encolhido num esgar de contentamento arrogante, os dois senhores trocavam palavras breves, códigos monossilábicos, apontando espasmodicamente os dedos numa posição apropriada do livro, com um clarão de adivinhos nos olhos. Aos poucos a discussão esquentava, percebia-se uma irritação, controlada dificuldade [...]. A situação se

\footnotetext{
${ }^{2}$ Disponível em: $<$ https://www.youtube.com/watch?v=-p870MeyJuw $>$.
} 
agravava. Houve um momento em que ambos se ergueram de seus lugares e ficaram quase fora de si [...] (SCHULZ, 2012, p. 243).

Mais tarde, depois da intercessão da mãe do narrador, ele observou que as expressões de seu pai e do visitante "prometiam muito. Piscando o olho aos vendedores, dava a entender que agora estavam cheios de iniciativa." (SCHULZ, 2012, p. 244).

Assim como o narrador do conto de Schulz, assisti à peça de Kantor tentando decifrar a expressão dos atores, que me permitia, em certa medida, "entender" o que acontecia em cena: os/as atores/atrizes traduziram a peça para mim.

Fato semelhante aconteceu, afirmaria, quando li o mencionado conto de Bruno Schulz em português. Alguém o "encenou” para mim, alguém o encenou na minha língua, não com gestos, mas com palavras. Nesse caso, o encenador foi Henryk Siewierski, responsável pela tradução para o português do Brasil do livro Ficção completa: Bruno Schulz (Cosac Naify, 2012).

Comparo, portanto, o tradutor ao ator, valendo-me da definição de Tadeusz Kantor para quem

o ator é um 'jogador' que joga com o texto, se distancia dele, aproximase dele, o abandona e o retoma, tira-lhe todo caráter anedótico para revelá-lo em sua abstração concreta. É um jogador que não sublinha a convenção do jogo, mas afirma com força sua realidade de jogador, tal como o saltimbanco ou o clown na arena do circo (KANTOR, 2008, p. 37).

A propósito do ator, lembra Kantor que, se ele "imita uma ação se coloca forçosamente acima dela. $\mathrm{O}$ ator que a executa realmente se coloca em relação a ela em posição de igualdade. É assim que se modifica a hierarquia fundamental: objeto-ator, ação-ator" (KANTOR, 2008, p. 37).

A ideia do teórico do teatro polonês parece dialogar com o conceito de tradução ou transcriação de Haroldo de Campos, que se fundamenta em parte nas ideias do alemão Wolfgang Iser. Segundo Campos, é preciso desmistificar "a 'ideologia da fidelidade', a ideia servil da tradução-cópia” (CAMPOS, 2013, p. 120). É necessário pensar "a própria tradução enquanto ficção". Haroldo vale-se de um ensaio de Iser - Os atos de fingir ou o que é fictício no texto ficcional? - para descrever e reforçar "uma 'relação triádica' que se estabelece entre o real, o fictício e o imaginário" na tradução. (CAMPOS, 2013, p. 121).

Aproveitando essa imagem de jogo entre o real, o fictício e o imaginário proposto por Haroldo de Campos via Iser e a imagem circense de Tadeusz Kantor, diria que o 
tradutor seria igualmente um mágico, que brinca com a tríade (real, imaginário e fictício). O mágico tira coelhos da cartola; esquarteja mulheres e homens dentro de caixas, separa suas partes, e depois os faz ressurgir inteiros em outro lugar. Não é isso que faz o tradutor?

Foi isso, diria, que fez Siewierski quando traduziu Bruno Schulz. Como leitora, diante dos meus olhos, ele tirou de sua cartola, não sem antes ter esquartejado, com o objetivo de ver suas entranhas, o texto do escritor em polonês, e o fez ressurgir, inteiro, em outro lugar, em outra língua, a portuguesa.

Tomasz Barciński, tradutor do romance Ferdydurke, de Witold Gombrowicz, afirmou, por exemplo, que traduzir o livro foi um grande desafio, pois o escritor tem

um estilo que, de acordo suas próprias palavras, é 'fantástico, excêntrico e bizarro, chegando à beira da mania, da loucura, do disparate'. Além disso, ele criou palavras inexistentes em polonês e, para complicar ainda mais, deu um significado diferente a algumas palavras existentes, não raro transformando substantivos em verbos, verbos em adjetivos e estes últimos em verbos (GOMBROWICZ, 2006, p. 345).

Nesse caso, o próprio escritor é cheio de truques, os quais o tradutor precisaria conhecer "no intuito de decifrar o significado pretendido pelo autor", como disse Barciński em um outro contexto (GOMBROWICZ, 2006, p. 345).

$\mathrm{O}$ tradutor, como o mágico, precisa conhecer o manual de magia e precisa ter a habilidade de enganar, de iludir o leitor, ou seja, de fazer com que ele pense que lê, por exemplo, Gombrowicz, quando, na verdade, lê também Barciński, ou os dois ao mesmo tempo em português.

Tradutor e autor não são as mesmas pessoas, mas o tradutor tem que se disfarçar e passar pelo autor e, para passar por ele, tem que ficar o mais parecido possível com ele. $\mathrm{O}$ tradutor de Gombrowicz lembra que antes de se aventurar a traduzir o mestre polonês adquiriu "a mais recente edição da tradução castelhana - a da Seix Barral, de 2004" (GOMBROWICZ, 2006, p. 346), e prossegue:

Qual não foi minha surpresa (e decepção) ao constatar que a versão castelhana era significativamente diferente do original polonês, com parágrafos inteiros suprimidos, novas passagens e frases com sentido diverso do que trazia a edição polonesa. Para mim fiou claro que o grupo de tradutores, contando com a anuência do autor, sentiuse à vontade para alterar o texto original - algo que eu, no entanto, contratado para traduzir diretamente do polonês, não tinha o direito de fazer. (GOMBROWICZ, 2006, p. 346). 
Essa preocupação é legítima, principalmente, vinda de um tradutor que não tem a anuência do autor do texto para fazer grandes modificações em sua obra. Aqui, cabe ao tradutor aplicar os truques que sabe fazer com a linguagem do idioma para o qual irá traduzir, a fim de que essa nova linguagem se assemelhe à do texto de partida.

É um truque, uma espécie de ilusão de ótica, como aquelas usadas pelos mágicos que nos fazem acreditar que é possível transformar uma flor num pássaro e que flor e pássaro são a mesma coisa.

A propósito do tradutor/mágico, ele tem ainda outro truque em seu repertório, o de se tornar, de repente, invisível, de sumir em cena. Recentemente o tradutor Piotr Kilanowski, com quem tenho dialogado mais estreitamente e que tem me introduzido à literatura polonesa, traduziu Eu construía a barricada, da escritora polonesa Anna Świrszczyńska (1909-1984). O livro foi publicado por uma pequena editora de Curitiba, Dybbuk, e é um relato contundente sobre o Levante de Varsóvia, um dos acontecimentos mais assombrosos da Segunda Grande Guerra, quando, em 1944, os poloneses lutaram durante 63 dias para libertar a capital do país do controle nazista. Por meio da tradução de Kilanowski, o leitor brasileiro poderá testemunhar esse acontecimento bárbaro que não fez parte da história do Brasil.

O relato de guerra de Anna Swir, como a escritora é conhecida em países anglofalantes, é desconcertante e narrado de forma seca e direta, sem nenhum sentimentalismo, como se a autora estivesse "entorpecida" por tudo que presenciou, pelo menos é assim que nos chegam seus versos na tradução de Kilanowski para o português:

\author{
Rezam em voz alta a ladainha pelos moribundos, \\ emudecem \\ no meio da palavra. \\ O bombardeiro mergulha acima do telhado. \\ Passou. \\ Estrondo. A morte abateu outra casa, outras pessoas. \\ Respiram, volta-lhes a fala. \\ - Essa caiu mais longe, senhor. \\ - Que sorte, senhora. (ŚWIRSZCZYŃSKA, 2017, p. 19).
}

Há que se destacar ainda, como lembra Kilanowski (2017) em seu esclarecedor texto introdutório, que Anna é uma escritora feminista, "talvez a mais importante poeta feminina polonesa depois da guerra", que apresenta "a sexualidade e a corporalidade 
femininas em suas glórias e sofrimentos" (ŚWIRSZCZYŃSKA, 2017,p. 8). Anna descreve soldados (mulheres) de cabelos longos e corpos destroçados; escoteiras que lutam como soldado e sonham estar num baile - "Quando morreu lhe puseram o vestido/ e ficaram as quatro em posição de sentido/ junto à sua cama por uma hora" (ŚWIRSZCZYŃSKA, 2017, p. 95) -, e mães que agonizam enquanto seus filhos vão à luta e as esquecem.

Eu construía a barricada é um relato de guerra do ponto de vista da mulher, ainda que a autora soubesse que "a guerra não tem rosto de mulher". Cabe destacar, contudo, que na sua epopeia da guerra a mulher não é uma heroína; ela é apenas a testemunha da história: "Filhinha, eu não fui uma heroína/ as barricadas sob o tiroteio, todos construíram/ mas eu vi heróis/ e sobre isso preciso falar" (ŚWIRSZCZYŃSKA, 2017, p. 15).

A propósito da voz feminina na obra de Anna Swir, recebi de Kilanowski, em primeira mão, alguns poemas já vertidos para o português por ele próprio em que ela discorre sobre a questão da mulher de modo amplo. São poemas de cunho feminista, nos quais ela contesta o papel da mulher na sociedade e dentro de uma história que vem sendo contada há séculos. Diz o poema Coragem:

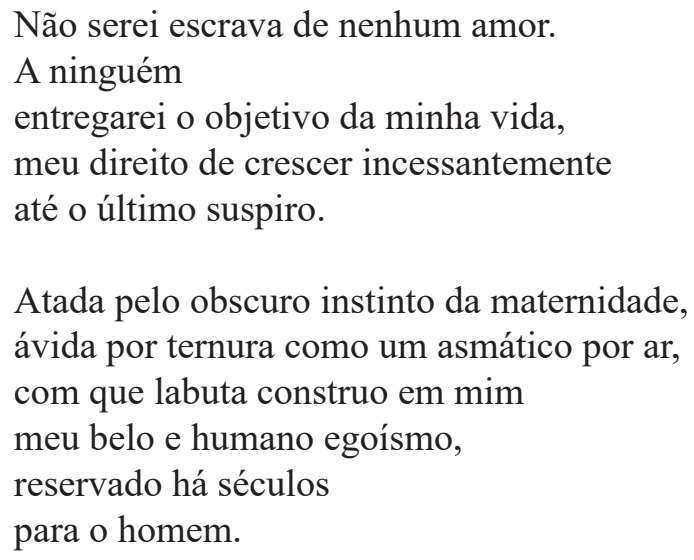

Leio os poemas de Anna Swir, ouço a voz da poeta, mas por trás dessa voz em português há uma voz masculina, a voz do tradutor, que, tal como mágico, em algum momento sumiu de cena, iludiu o leitor, no caso a leitora, eu.

Aliás, estar presente e ter que desaparecer, esse é, diria, o paradoxo em que vive o tradutor, que é, em certo sentido, coautor do texto, pois o que lemos em uma tradução é a leitura do tradutor. Mas ainda que seja coautor, o tradutor precisa ficar invisível para que seu texto seja convincente e que ele se passe por outro que ele não é.

A esse respeito, vale lembrar, contudo, que, como diria Kantor, o ator, comparado aqui com o tradutor, é um 


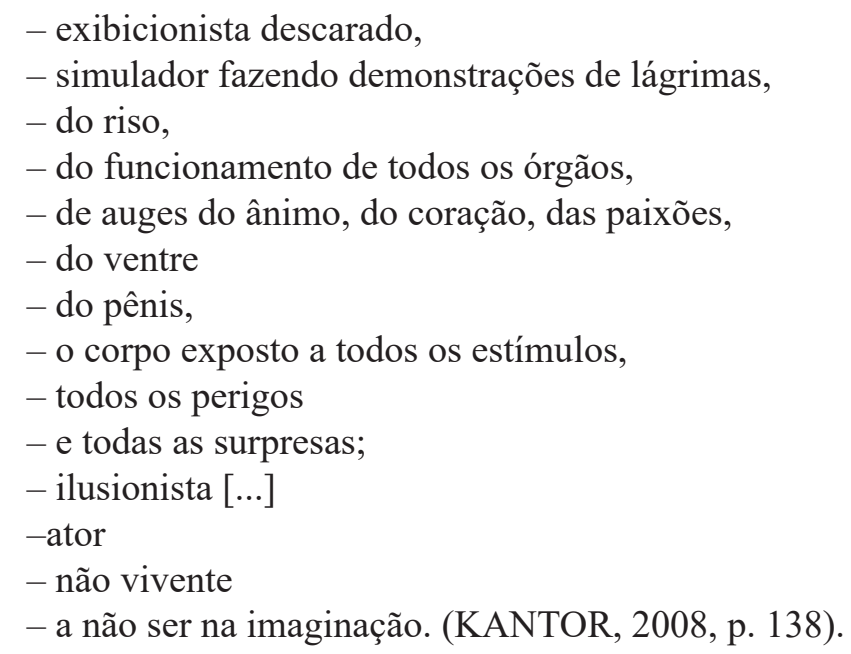

Voltemos ao mágico, ele é também quem traz à luz o que estava escondido no punho da manga da camisa dele ou do espectador, ou o que estava atrás da orelha do espectador. Assim, é o tradutor que traz à luz outra cultura, outra forma de ver o mundo, outros conceitos; a tradução enriquece a língua. Sem tradução ficamos como os seres do poema "O Senhor Cogito - anotações da casa morta", de Zbigniew Herbert, em tradução de Piotr Kilanowski, "enfileirados no fundo do templo do absurdo// [...] como frutos caídos da árvore da vida/ apodrecendo separadamente/ cada um à sua maneira" (HERBERT, 2017, s/n).

É assim, por meio da tradução, que conheço a literatura polonesa, a cultura polonesa, que se impregnam na minha cultura, na minha escrita em português, no meu país, tão distante da Europa, da Polônia. Por essa tradução, de repente, pode-se perceber que o Brasil não está tão longe da Polônia, que em algum momento nossas histórias se cruzam, que há muito em comum entre nós. Quando Anna Swir escreve sobre o Levante de Varsóvia, por vezes pensamos que ela bem poderia estar falando sobre a vida dos jovens em muitas comunidades pobres espalhadas pelo Brasil. Diz o poema Os braços que choram, da poeta polonesa:

\footnotetext{
Sua morte tem dezesseis anos

Agonizando ensanguentada na calçada como vai saber que está agonizando.

Está tão completamente preenchida de juventude, que até sua agonia é jovem.

Não sabe morrer.
}

Afinal, é a primeira vez que está morrendo. (ŚWIRSZCZYŃSKA, 2017, p. 167). 


\section{REFERÊNCIAS:}

CAMPOS, Haroldo. Da transficcionalidade: o tradutor como transfingidor. In: TÁPIA, Marcelo; NÓBREGA, Thelma Médici (orgs.). Haroldo de Campos - transcriação. São Paulo: Perspectiva, 2013, p. 118-130.

GOMBROWICZ, Witold. Ferdydurke. Tradução: Tomasz Barciński. São Paulo: Companhia das Letras, 2006.

HERBERT, Zbigniew. O Senhor Cogito - anotações da casa morta. In: POEMAS de Zbigniew Herbert - Traduções de Piotr Kilanowski, Qorpus, n. 24, 2017. Disponível em: $<$ https:/qorpus.paginas.ufsc.br/teatro-na-praia/edicao-n-024/poemas-de-zbigniewherbert-traducoes-de-piotr-kilanowski/>. Acesso em 21 ago. 2020.

KANTOR, Tadeusz. O Teatro da morte. Vários tradutores. São Paulo: Perspectiva: Edições SESC SP, 2008.

KILANOWSKI, Piotr. A poesia contra os mitos - palavra introdutória. In: ŚWIRSZCZYŃSKA, Anna. Eu construía a barricada. Tradução de Piotr Kilanowski. Curitiba: Dybbuk, 2017.

SCHULZ, Bruno. Ficção completa: Bruno Schulz. Tradução e posfácio: Henryk Siewierski. São Paulo: Cosac Naify, 2012.

ŚWIRSZCZYŃSKA, Anna. Eu construía a barricada. Tradução de Piotr Kilanowski. Curitiba: Dybbuk, 2017. 